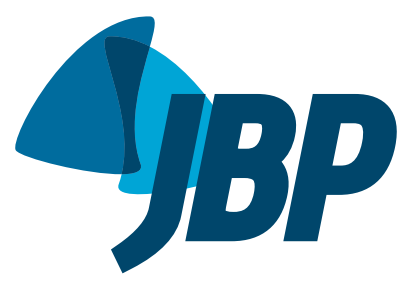

1. Clínica de Tuberculosis, Instituto Nacional de Enfermedades Respiratorias - INER - Ciudad de México, México.

2. Centro de Investigación, Prevención y Tratamiento de Infecciones Respiratorias, Hospital Universitario, Universidad de Monterrey, Monterrey, México.

3. WHO Collaborating Centre for TB and Lung Diseases, Fondazione Salvatore Maugeri, Istituto di Ricovero e Cura a Carattere Scientifico - IRCCS - Tradate, Italia.

4. Public Health Consulting Group SAGL, Lugano, Switzerland.

5. Servicio de Neumología, Hospital General Dr. José Ignacio Baldó, El Algodonal, Caracas, Venezuela.

6. Fundación Neumológica Colombiana, Universidad de La Sabana, Bogotá, Colombia.

7. Instituto de Doenças do Tórax Universidade Federal do Rio de Janeiro, Rio de Janeiro (RJ) Brasil.

8. Centro de Referência Hélio Fraga, Escola Nacional de Saúde Pública Sergio Arouca, Fundação Oswaldo Cruz, Rio de Janeiro (RJ) Brasil.

9. Clínica del Sueño, Instituto Nacional de Enfermedades Respiratorias - INER Ciudad de México, México.

10. Unità di Pneumologia, Fondazione Salvatore Maugeri, Istituto di Ricovero e Cura a Carattere Scientifico - IRCCS Tradate, Italia.

11. Dipartimento di Medicina Clinica e Sperimentale, Università dell'Insubria, Varese, Italia.

Submitted: 28 July 2016

Accepted: 1 September 2016.

Study carried out under the auspices of the World Health Organization

Collaborating Centre for Tuberculosis and Lung Diseases, Fondazione Salvatore

Maugeri, Istituto di Ricovero e Cura a

Carattere Scientifico - IRCCS - Tradate, Italia.

\section{Is there a rationale for pulmonary rehabilitation following successful chemotherapy for tuberculosis?}

Marcela Muñoz-Torrico', Adrian Rendon², Rosella Centis³, Lia D’Ambrosio ${ }^{3,4}$, Zhenia Fuentes ${ }^{5}$, Carlos Torres-Duque ${ }^{6}$, Fernanda Mello ${ }^{7}$, Margareth Dalcolmo ${ }^{8}$, Rogelio Pérez-Padilla9 ${ }^{9}$ Antonio Spanevello ${ }^{10,11}$, Giovanni Battista Migliori ${ }^{3}$

\begin{abstract}
The role of tuberculosis as a public health care priority and the availability of diagnostic tools to evaluate functional status (spirometry, plethysmography, and DLCO determination), arterial blood gases, capacity to perform exercise, lesions (chest X-ray and CT), and quality of life justify the effort to consider what needs to be done when patients have completed their treatment. To our knowledge, no review has ever evaluated this topic in a comprehensive manner. Our objective was to review the available evidence on this topic and draw conclusions regarding the future role of the "post-tuberculosis treatment" phase, which will potentially affect several million cases every year. We carried out a non-systematic literature review based on a PubMed search using specific keywords (various combinations of the terms "tuberculosis", "rehabilitation", "multidrug-resistant tuberculosis", "pulmonary disease", "obstructive lung disease", and "lung volume measurements"). The reference lists of the most important studies were retrieved in order to improve the sensitivity of the search. Manuscripts written in English, Spanish, and Russian were selected. The main areas of interest were tuberculosis sequelae following tuberculosis diagnosis and treatment; "destroyed lung"; functional evaluation of sequelae; pulmonary rehabilitation interventions (physiotherapy, long-term oxygen therapy, and ventilation); and multidrug-resistant tuberculosis.The evidence found suggests that tuberculosis is definitively responsible for functional sequelae, primarily causing an obstructive pattern on spirometry (but also restrictive and mixed patterns), and that there is a rationale for pulmonary rehabilitation. We also provide a list of variables that should be discussed in future studies on pulmonary rehabilitation in patients with post-tuberculosis sequelae.
\end{abstract}

Keywords: Tuberculosis/complications; Tuberculosis/rehabilitation, Tuberculosis/therapy; Quality of life; Diagnostic imaging; Respiratory function tests.

\section{INTRODUCTION}

The World Health Organization (WHO) estimated that $3.3 \%$ of the new cases of tuberculosis and $20 \%$ of the previously treated cases of the disease are due to multidrug-resistant tuberculosis (MDR) strains of Mycobacterium tuberculosis worldwide in 2014. The highest prevalences of MDR tuberculosis (MDR-TB) have been reported in Eastern European and Central Asian countries, although relatively high prevalence rates have been described in Latin America. As of today, the "world record" MDR-TB prevalence has been described in Belarus (34\% among new cases and $69 \%$ among retreatment cases), where $29 \%$ of the cases are reported to be extensively drug-resistant tuberculosis (XDR-TB).

It is unfortunately well known that outcomes of MDR-TB and XDR-TB cases (particularly those with a resistance pattern beyond XDR-TB) are poor, since the treatment success rate is below $20 \%$ and the failure and death rates combined are $49 \%$. ${ }^{(2,3)}$

The WHO has recently published two core documents addressing the critical importance of preventing the emergence of drug resistance, both underlining the relevance of managing MDR-TB adequately. ${ }^{(1,4-8)}$ The WHO action framework "Towards tuberculosis elimination for low-incidence countries" presents eight priority action areas, two of which are focused on, namely, (action \#5) optimizing the management of MDR-TB and (action \#7) investing in research on new diagnostic tools and drugs. $(1,4,6,9)$

Correspondence to:

Giovanni Battista Migliori. World Health Organization Collaborating Centre for Tuberculosis and Lung Diseases, Fondazione Salvatore Maugeri, Istituto di Ricovero e Cura a Carattere Scientifico, Via Roncaccio, 16, 21049, Tradate, Italia

Tel.: 390331 829404; Fax: 390331 829402. E-mail: giovannibattista.migliori@fsm.it

Financial support: None. 
However, the scientific and programmatic focus is presently on diagnosis and treatment of the disease, whereas post-cure follow-up is seen as an approach to evaluate the proportion of relapse, particularly in MDR-TB/XDR-TB cases.

The role that tuberculosis plays as a public health care priority, as well as the importance of diagnostic tools being available in order to evaluate the patients thoroughly, by means of their functional status-via spirometry, plethysmography, and determination of DLCO - arterial blood gas analyses, their capacity to perform exercise-via the six-minute walk test (6MWT)the description of their lesions-via chest X-rays (CXRs) and CT-and their quality of life (QoL)-via the Saint George's Respiratory Questionnaire (SGRQ)-justifies the effort to consider what needs to be done when patients have completed their treatment successfully. This vision has ethical, clinical, organizational, programmatic, and economic implications.

To our knowledge, the follow-up of tuberculosis patients who completed their treatment has never been reviewed in a comprehensive manner in the literature. Therefore, the objective of the present study was to review the available evidence on this topic and to draw some conclusions regarding the future role of the "post-tuberculosis treatment" phase, which will potentially have an impact on several million cases every year around the globe.

\section{METHODS}

We carried out a non-systematic review of the literature based on a PubMed search using specific keywords, including various combinations of the terms "tuberculosis", "rehabilitation", "MDR-TB", "pulmonary disease", "obstructive lung disease", and "lung volume measurements". The reference lists of the most important studies were also retrieved in order to improve the sensitivity of the research. Manuscripts written in English, Spanish, and Russian were selected. The main areas of interest that we identified in order to describe the topic were as follows:

1. Tuberculosis sequelae following diagnosis and treatment of tuberculosis

2. Destroyed lung

3. Functional evaluation of sequelae

4. Pulmonary rehabilitation (PR) interventions, such as physiotherapy, long-term oxygen therapy (LTOT), and ventilation

5. MDR-TB

After describing each of these areas of interest, we will provide a summary of the evidence compiled from the literature search (Table 1) and concluding remarks.

\section{TUBERCULOSIS SEQUELAE FOLLOWING DIAGNOSIS AND TREATMENT OF TUBERCULOSIS}

Although the potential role of PR has been clearly underlined in a study discussing the role of the new WHO recommendations on shorter treatment regimens, ${ }^{(10)}$ the concept that rehabilitation is a component of tuberculosis treatment is as old as that of sanatoria. ${ }^{(11,12)}$ In 1964, Chapman and Hollander wrote that, based on their experience with 454 patients with active tuberculosis "placed on a program of intensive physical exercise, combined with chemotherapy," "the concept of minimum exercise and prolonged bed rest in the hospital and a prolonged convalescent period after discharge is no longer justified."(12)

In 2006, a group of authors in India ${ }^{(13)}$ prospectively studied the clinical presentation and predictors of outcome in 116 patients with acute exacerbations of COPD who had to be admitted to the ICU and found that $28.4 \%$ of those had had pulmonary tuberculosis previously. Among those patients, some required invasive mechanical ventilation and a few died. The authors concluded that "an intriguing relationship" existed among smoking, pulmonary tuberculosis, and COPD "which merits further study."(13)

In 2010, Jordan et al. ${ }^{(14)}$ wrote that "the global prevalence of bronchiectasis, a recognized sequela of tuberculosis, is unknown, but is by no means insignificant. The pathophysiology of chronic airflow obstruction in both of these diseases is poorly understood, but it is associated with an accelerated rate of loss in pulmonary function."

Hassan and Al-Jahdali(15) reported that "in addition to its acute clinical consequences, patients with pulmonary tuberculosis may be left with significant long-term sequelae," "associated with considerable morbidity, mortality, and health expenditure," and commented that both obstructive and restrictive functional abnormalities were present.

Shah and Reed ${ }^{(16)}$ described, among the commonest complications of tuberculosis, "mycetomas developing within residual tuberculosis cavities, impaired pulmonary function, or focal neurologic deficits from tuberculomas," and, therefore, "public health tuberculosis programs and health systems require additional resources to provide comprehensive tuberculosis and post-tuberculosis care."

Bansal and Prasad ${ }^{(17)}$ commented that "COPD, interstitial lung disease, tuberculosis, and lung cancer together are the leading causes of morbidity and mortality," which are "increasing all over the world"; they also stated that "early fatigue and breathlessness" make patients "socially isolated and depressed". Functional disability and repeated hospitalizations reduce the efficiency of the patients at home and at work place, being associated with increased expenditures and utilization of health care systems, which results in a socioeconomic burden. PR, an evidence-based, multidisciplinary, and comprehensive non-pharmacological intervention, has emerged as a recommended standard of health care for patients suffering from respiratory diseases. PR is advised for patients with chronic lung conditions who have dyspnea or other respiratory symptoms, reduced exercise tolerance, restriction in activities, or impaired health status despite optimal pharmacological treatment. Early leaders observed two centuries ago 


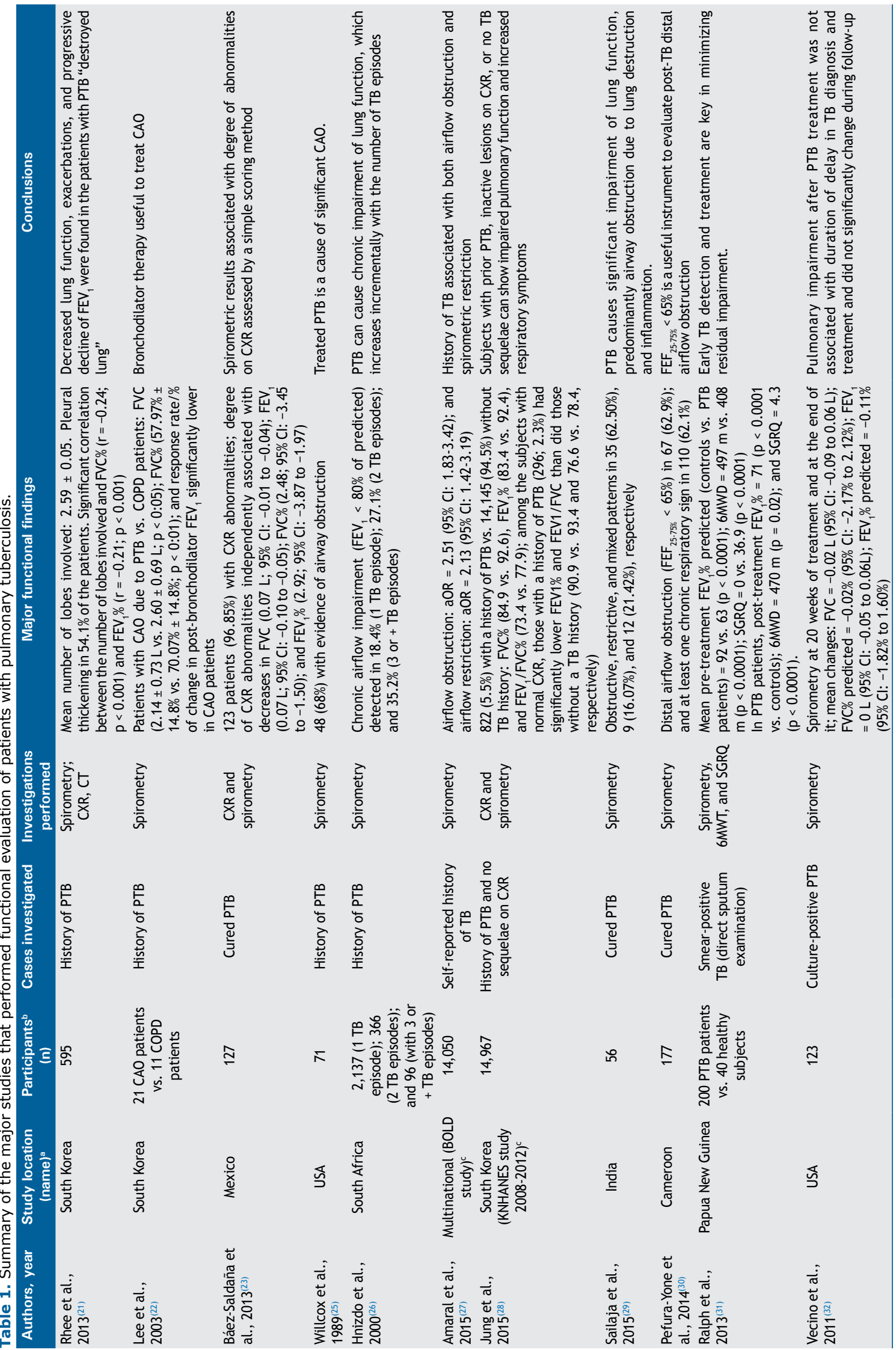




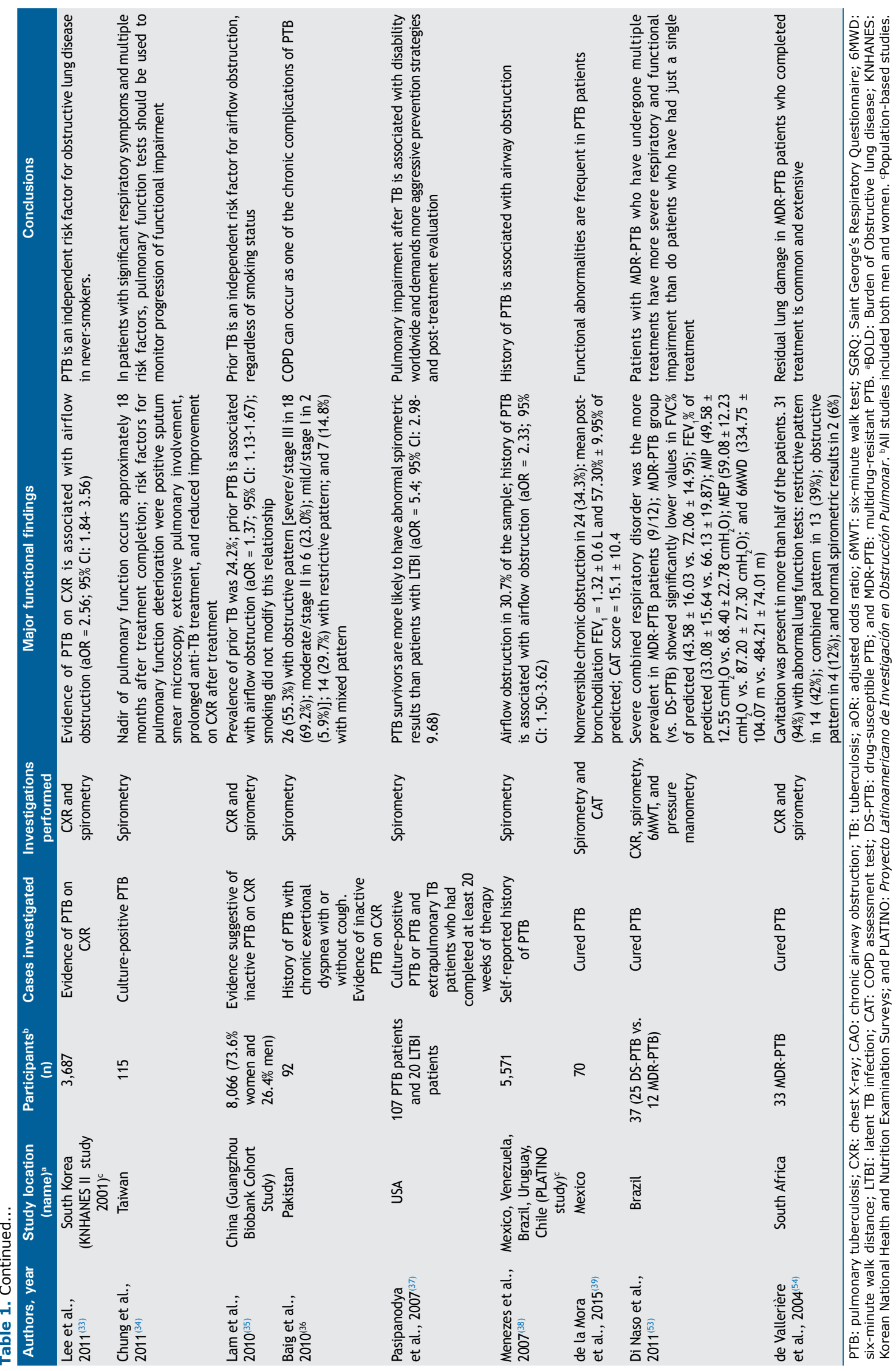


that exercise is an important element in the care of patients with lung and heart diseases, especially in tuberculosis. $^{(17)}$

In a recent American Thoracic Society (ATS)/European Respiratory Society (ERS) statement, as well as in a guideline from South Africa for the management of COPD, tuberculosis is clearly among the diseases that require the use of $P R$. $^{(18,19)}$

\section{"DESTROYED LUNG"}

Late diagnosis is often responsible for extensive bilateral lesions, usually due to bronchiectasis, scarring, parenchymal deformation, lung volume loss, and pleural thickening, which might develop to the so-called "destroyed lung" (Figure 1). ${ }^{(20)}$

Two studies described the effect of "destroyed lung" on the pulmonary function of patients treated for pulmonary tuberculosis, both carried out in South Korea. ${ }^{(21,22)}$ Rhee et al. ${ }^{(21)}$ studied 595 tuberculosis patients from 21 hospitals between 2005 and 2011. The mean extension of the lesions was $2.59 \pm 0.05$ lobes, and pleural thickening was observed in $54.1 \%$ of the patients. Various lung function parameters were reduced (mean values): $\mathrm{FVC}=2.06 \pm 0.03 \mathrm{~L}(61.26 \%$ $\pm 0.79 \%$ of predicted); $\mathrm{FEV}_{1}=1.16 \pm 0.02 \mathrm{~L}(49.05 \%$ $\pm 0.84 \%$ of predicted); $\mathrm{FEV}_{1} / \mathrm{FVC}$ ratio $=58.0 \% \pm$ $0.70 \%$; bronchodilator response $=5.70 \% \pm 0.34 \%$; and number of exacerbations/year $=0.40 \pm 0.04$. The number of lobes involved significantly correlated with FVC, $\mathrm{FEV}_{1}$, and the number of exacerbations/ year. The use of long-acting muscarinic antagonists or long-acting $\beta_{2}$ agonists plus inhaled corticosteroids achieved bronchodilator effects. Initial $\mathrm{FEV}_{1} \%$ and the number of exacerbations during follow-up were independent factors affecting $\mathrm{FEV}_{1}$ deterioration in the multivariate analysis.

Lee et al. (22) investigated lung function and post-bronchodilator response in 21 patients with

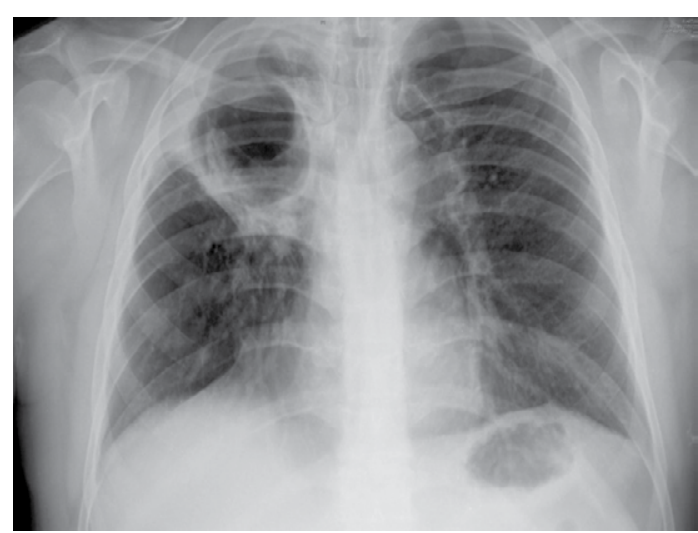

Figure 1. Chest X-ray of a 39-year-old male patient with a history of pan-susceptible tuberculosis treated for six months in 2007. The patient was considered cured. Later in time, he reported a six-month history of cough, mild dyspnea, but no fever. Tuberculosis relapse was ruled out; sputum smear microscopy and culture were negative. The image shows a giant cavity in the right upper lobe and some fibrotic changes. "destroyed lung"-related chronic airflow obstruction against a cohort of COPD patients matched by sex, age, and pulmonary function parameters. The mean FVC values (both in $L$ and in \% of predicted) of the patients with "destroyed lung" were significantly lower than those of the COPD patients $(2.14 \pm 0.73 \mathrm{~L}$ vs. $2.60 \pm 0.69 \mathrm{~L}$ and $57.9 \% \pm 14.8 \%$ vs. $70.0 \pm 14.8 \%$, respectively). The tuberculosis patients presented with significantly lower FVC and post-bronchodilator FEV than did the COPD patients. In addition, among the tuberculosis patients, those with wheezing symptoms showed significantly lower $\mathrm{FEF}_{25-75 \%}$ and higher airway resistance than did those without wheezing. Tuberculosis patients with wheezing responded better to the bronchodilator than did those without it. The authors concluded that bronchodilator therapy could be useful in those patients.

In Mexico, 127 cured tuberculosis patients underwent spirometry and CXR; 123 (96.85\%) exhibited some degree of radiographic abnormalities. ${ }^{(23)}$ The extent of lung damage was measured by dividing the lung parenchyma into four quadrants and scoring it from 0 to 5; the mean number of radiographic abnormalities was $6.45 \pm 4.14$. In that sample, 30 patients $(24 \%)$ showed an obstructive spirometric pattern, and 22 $(17 \%)$, a restrictive pattern; only $15(12 \%)$ had a positive bronchodilator test, and $21(17 \%)$ had an $\mathrm{SpO}_{2}$ $<90 \%$. The adjusted multilinear regression model showed that the degree of radiographic abnormalities was independently associated with a decrease in the absolute values of FVC $(0.07 \mathrm{~L} ; 95 \% \mathrm{CI}:-0.01$ to $-0.04)$ and $\mathrm{FEV}_{1}(0.07 \mathrm{~L} ; 95 \% \mathrm{CI}:-0.10$ to -0.05 ; $\mathrm{p}<0.001)$; as well as in their \% of predicted values (FVC $=2.48 \% ; 95 \% \mathrm{CI}:-3.45$ to -1.50 ; and $\mathrm{FEV}_{1}$ $=2.92 \% ; 95 \% \mathrm{CI}:-3.87$ to -1.97$)$. That study showed that spirometric values were associated with the degree of radiographic abnormalities assessed by a simple scoring method.

\section{FUNCTIONAL EVALUATION OF SEQUELAE}

Several studies investigated the mechanical lung function in tuberculosis patients (Figure 2).

Already in 1961, Hallet and Martin ${ }^{(24)}$ described the diffuse obstructive pulmonary syndrome (measured via the maximal expiratory flow rate) in $34 \%$ of 710 tuberculosis patients admitted to a sanatorium during a one-year period. The factors significantly associated with the incidence of that syndrome were age, severity of tuberculosis, and some comorbidities (bronchial asthma, pulmonary malignancy, frequent and protracted chest colds, and silicosis). The authors concluded that the measurement of maximal expiratory flow rate is a useful tool in determining diffuse obstructive pulmonary disease.

Willcox and Ferguson(25) investigated 71 patients previously treated for tuberculosis up to 16 years prior. Evidence of airway obstruction was found in 48 (68\%) of the patients. An inverse relationship between the extent of the disease on the original CXRs and FEV 
was identified. The authors identified a similar inverse relationship of the amount of sputum produced with $\mathrm{FEV}_{1}$ and with the extent of the disease on the CXRs. The authors concluded that treated tuberculosis is a cause of COPD.

In a large study in South Africa, (26) a cohort was followed in order to study the chronic effect of initial and recurrent pulmonary tuberculosis: 27,660 black South African gold miners who had reliable pulmonary function test results between January of 1995 and August of 1996 were retrospectively followed for the incidence of tuberculosis to 1970. In that cohort of miners, 2,137; 366; and 96 had had, respectively, one, two, and three or more episodes of tuberculosis. The mean time between the diagnosis of the last episode of tuberculosis and lung function testing was 4.6 years (range: 1-372 months). The loss of lung function was the highest within the first 6 months after tuberculosis being diagnosed and stabilized after 12 months, when the loss was considered chronic. The estimated mean deficits in $\mathrm{FEV}_{1}$ after one, two, and three or more episodes of tuberculosis were $153 \mathrm{~mL}, 326 \mathrm{~mL}$, and 410 $\mathrm{mL}$, respectively, whereas the corresponding deficits in FVC were $96 \mathrm{~mL}, 286 \mathrm{~mL}$, and $345 \mathrm{~mL}$. The loss of lung function was similar in HIV-positive and HIV-negative individuals. The proportion of individuals with chronic airflow impairment $\left(\mathrm{FEV}_{1}<80 \%\right.$ of predicted) was $18.4 \%, 27.1 \%$, and $35.2 \%$, respectively, in those with one, two, and three or more episodes of tuberculosis. The authors concluded that tuberculosis can cause chronic impairment of lung function, which increases with the number of episodes of the disease, and that early diagnosis and treatment of tuberculosis coupled with the prevention of HIV, silica dust exposure, silicosis, and poverty are important interventions.

In a recent multicenter, cross-sectional, general population-based study, ${ }^{(27)}$ the association of having a history of tuberculosis with airflow obstruction and spirometric abnormalities was studied in adults. A self-reported history of tuberculosis was associated with airflow obstruction (adjusted OR $=2.51 ; 95 \% \mathrm{CI}$ : 1.83-3.42) and spirometric restriction (adjusted OR $=2.13 ; 95 \% \mathrm{CI}: 1.42-3.19)$. The authors concluded that a history of tuberculosis was associated with both airflow obstruction and spirometric restriction, and should be considered as an important cause of obstructive disease and impaired lung function, particularly where tuberculosis is common.

In a study performed in South Korea between 2008 and 2012, (28) lung function impairment and persistency of respiratory symptoms were studied in 14,967 adults with and without a history of pulmonary tuberculosis. The adults were also divided into two groups: those showing residual sequelae on CXR and those without showing it in order to determine the risk factors for airflow obstruction. Among the population studied, 822 participants $(5.5 \%)$ had been treated for pulmonary tuberculosis (mean) 29.0 years prior to study initiation. The individuals with a history of tuberculosis, when compared with those without that, presented with significantly lower FVC\% (84.9 vs. 92.6), $\mathrm{FEV}_{1} \%$ (83.4 vs. 92.4), and $\mathrm{FEV}_{1} / \mathrm{FVC} \%$ (73.4 vs. 77.9). Among the 12,885 subjects with no sequelae on CXR, those with a history of pulmonary tuberculosis ( $n=296 ; 2.3 \%$ ) had significantly lower $\mathrm{FEV}_{1} \%$ (90.9 vs. 93.4) and $\mathrm{FEV}_{1} / \mathrm{FVC} \%$ (76.6 vs. 78.4). Subjects with a history of pulmonary tuberculosis but no sequelae on CXR reported a significantly higher frequency of cough and physical activity limitations due to pulmonary symptoms than those without that history ( $p<0.001$ for both). A history of pulmonary tuberculosis $(O R=2.314)$, along with older age, male gender, asthma, and smoking were independent risk factors for airflow obstruction. Finally, the study suggested that inactive tuberculosis lesions on CXR (OR = 2.3) were risk factors for airflow obstruction in subjects with a history of pulmonary tuberculosis. The authors concluded that the patients treated for tuberculosis should undergo regular lung function testing and stop smoking in order to prevent chronic airway disease.

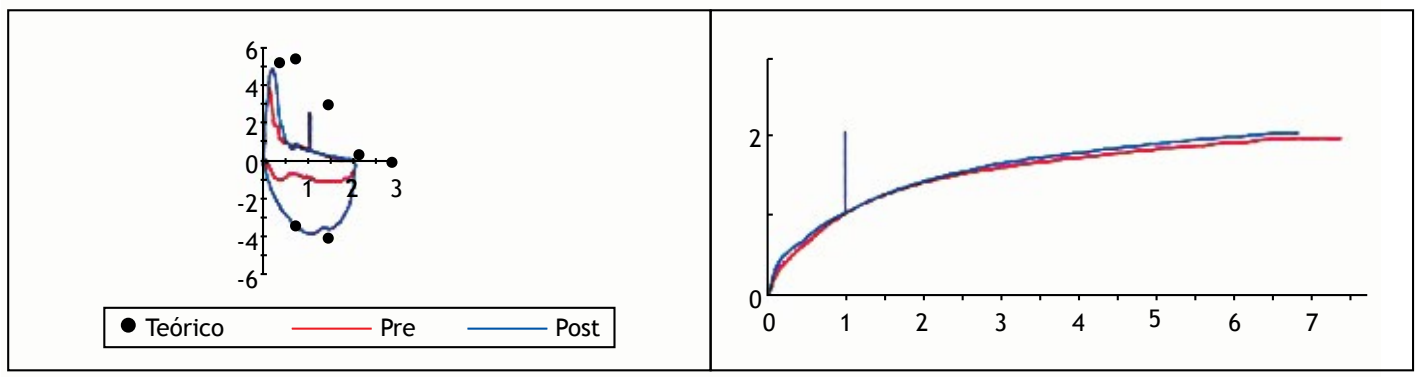

\begin{tabular}{|c|c|c|c|c|c|c|}
\hline \multirow[b]{2}{*}{-.ESPIRO } & \multicolumn{3}{|c|}{ Pre-Bronch } & \multicolumn{3}{|c|}{ Post-Bronch } \\
\hline & $\underline{\text { Real }}$ & $\underline{\text { Teórico }}$ & \%Teórico & Real & \%Teórico & \%Cambio \\
\hline$=V C(L)$ & 1.99 & 2.85 & 69 & 2.04 & 71 & +2 \\
\hline FEV1 (L) & 1.05 & 1.63 & 64 & 1.06 & 65 & + \\
\hline FEV1/FVC (\%) & 53 & 71 & 74 & 52 & 73 & \\
\hline
\end{tabular}

Figure 2. Spirometry of the same patient shown in Figure $1 . \mathrm{FEV}_{1} / \mathrm{FVC}$ ratio was below $70 \%$. $\mathrm{FEV}_{1}$ was decreased and unresponsive to bronchodilator. FVC was also diminished. Fixed airway obstruction was detected, and mild restriction was considered. The final diagnosis was pulmonary sequelae of tuberculosis. Espirometría: spirometry; teórico: predicted; pre/post bronch: pre-/post-bronchodilator; real: observed; and cambio: change. 
In a recent study, ${ }^{(29)} 56$ treated tuberculosis patients who were considered cured underwent simple spirometry, and pre- and post-bronchodilator FEV, FVC, FEV $/$ FVC ratio were recorded. Obstructive, restrictive, and mixed patterns were identified in $62.50 \%, 16.07 \%$, and $21.42 \%$ of the patients, respectively.

In a cross-sectional study ${ }^{(30)}$ involving 177 individuals who had been previously treated for tuberculosis in Cameroon between 2012 and 2013, spirometry was performed in order to evaluate the clinical impact of low $\mathrm{FEF}_{25-75 \%}$. Distal airflow obstruction (DAO) was defined by an $\mathrm{FEF}_{25-75 \%}<65 \%$ and a $\mathrm{FEV}_{1} / \mathrm{FVC}$ ratio $\geq$ 0.70 . At least one chronic respiratory sign was present in $110(62.1 \%)$ of the participants, and DAO was identified in 67 (62.9\%). Duration of symptoms prior to the diagnosis of tuberculosis $>3$ months (adjusted $O R=2.91)$ and presence of $D A O(O R=2.22)$ were independent determinants that were significantly associated with persisting respiratory signs. The authors concluded that $\mathrm{FEF}_{25-75 \%}<65 \%$ is a useful instrument to evaluate post-tuberculosis DAO.

In Papua New Guinea, presently a hot spot for MDR-TB, a study ${ }^{(31)}$ evaluated morbidity during treatment and residual pulmonary disability in pulmonary tuberculosis cases undergoing spirometry, 6MWT, and evaluation of QoL (SGRQ). The authors evaluated 200 pulmonary tuberculosis patients (at baseline and after 6 months of treatment) and 40 healthy volunteers. The distance walked in the 6MWT (6MWD) was $497 \mathrm{~m}$ in controls vs. $408 \mathrm{~m}$ in tuberculosis patients at baseline ( $p$ $<0.0001$ ) and $470 \mathrm{~m}$ after 6 months ( $p=0.02$ ), whereas the SGRQ score was zero in controls vs. 36.9 in tuberculosis patients at baseline $(p<0.0001)$ and 4.3 after 6 months $(p<0.0001)$. The mean predicted $\mathrm{FEV}_{1}$ was $92 \%$ in controls vs. $63 \%$ among tuberculosis patients at baseline $(p<0.0001)$ and $71 \%$ after 6 months ( $p<0.0001)$. After six months of treatment, $27 \%$ of the tuberculosis patients still showed at least moderate-to-severe pulmonary function impairment, and $57 \%$ had respiratory symptoms, although most of them achieved "successful" treatment outcomes and self-reported good QoL. More advanced disease at baseline (longer illness duration and worse results on CXR at baseline) and HIV-positive status predicted residual disability. The authors concluded that early detection and treatment of tuberculosis are key in minimizing residual impairment.

Post-pulmonary tuberculosis impairment was studied after 20 weeks of tuberculosis treatment and again on, or after, treatment completion. (32) The median duration between the first and the second spirometry was 15 weeks. The mean change in FVC was $-0.02 \mathrm{~L}(95 \%$ CI: -0.09 to $0.06 \mathrm{~L}$ ), and that in $\mathrm{FVC} \%$ of predicted was $-0.02 \%$ ( $95 \% \mathrm{CI}:-2.17 \%$ to $2.12 \%$ ), whereas that in $\mathrm{FEV}_{1}$ was $0 \mathrm{~L}(95 \% \mathrm{CI}:-0.05$ to 0.06$)$, and that in $\mathrm{FEV}_{1} \%$ of predicted was $-0.11 \%$ (95\% CI: -1.82 to 1.60). Pulmonary impairment was not related to the delay in tuberculosis diagnosis or treatment, older age, or smoking habits.
The relationship between previous tuberculosis and the risk of COPD was studied in South Korea in a population-based investigation ${ }^{(33)}$ involving 3,687 individuals performing spirometry and CXR. Among those, 294 subjects had radiological evidence of previous tuberculosis with no evidence of active disease. Radiological evidence of previous tuberculosis was independently associated with airflow obstruction (adjusted OR $=2.56$ ) after adjustments for sex, age, and smoking history. Previous tuberculosis was still a risk factor (adjusted $O R=3.13$ ) with the exclusion of ever-smokers or subjects with advanced radiological lesions. Among the never-smokers, the proportion of subjects with previous tuberculosis on CXR increased as obstructive lung disease became more severe. The authors concluded that previous tuberculosis is an independent risk factor for COPD, even in never-smokers.

The trends toward deterioration of pulmonary function and its risk factors were studied in 115 patients with pulmonary tuberculosis after treatment completion. ${ }^{(34)}$ A model with a locally weighted scatterplot smoothing technique was used in order to evaluate the trends toward changes in pulmonary function. The median interval between the end of antituberculosis treatment and pulmonary function testing was 16 months. The nadir of pulmonary function occurred approximately 18 months after completion of the treatment. The risk factors associated with pulmonary function deterioration included positive sputum smear microscopy, extensive pulmonary involvement prior to antituberculosis treatment, prolonged antituberculosis treatment, and poor radiographic improvement after treatment. The authors concluded that pulmonary function testing should be used as a follow-up tool in order to monitor the progression of functional impairment, especially within the first 18 months after the completion of antituberculosis treatment.

A study in China(35) investigated the relationship between history of tuberculosis, smoking, and airflow obstruction in a population sample of 8,066 participants in the Guangzhou Biobank Cohort Study. The participants underwent spirometry, CXR, and a structured interview on lifestyle and exposures. Prior tuberculosis was defined as the presence of radiological evidence suggestive of inactive tuberculosis. In that sample, $24.2 \%$ of the individuals had a history of tuberculosis. After controlling for sex, age, and smoking exposure, prior tuberculosis remained independently associated with an increased risk of airflow obstruction (OR $=1.37 ; 95 \% \mathrm{CI}: 1.13-1.67)$. Further adjustments for exposure to passive smoking, biomass fuel, or dust did not alter that association. Smoking did not modify the association between prior tuberculosis and airflow obstruction. The authors concluded that prior tuberculosis is an independent risk factor for airflow obstruction, which might partly explain the high prevalence of COPD in China.

In a study in Pakistan, ${ }^{(36)}$ the prevalence of COPD was studied in 47 patients previously treated for pulmonary 
tuberculosis and reporting chronic exertional dyspnea with no other apparent cause. Of the 47 patients, 26 $(55.3 \%)$ showed an obstructive pattern on spirometry (severe in 18 , moderate in 6 , and mild in 2 ), whereas $14(29.7 \%)$ were found to have a restrictive pattern, and $7(14.8 \%)$ revealed a mixed obstructive and restrictive pattern.

In a case-control study, ${ }^{(37)}$ the lung function of 107 prospectively identified patients with pulmonary tuberculosis who had completed at least 20 weeks of therapy was compared with that of 210 patients with latent tuberculosis infection (LTBI). Impairment was present in $59 \%$ of the tuberculosis patients and in $20 \%$ of the LTBI control subjects. In comparison with the controls, the pulmonary tuberculosis patients showed significantly lower FVC, FEV FEV $_{1} /$ FVC ratio, and mid-expiratory phase of FEF. A VC $<50 \%$ of predicted was found in $10(9.40 \%)$ and $1(0.53 \%)$ of the patients, respectively, in the pulmonary tuberculosis and LTBI groups. In addition, a VC between $20 \%$ and $50 \%$ of the predicted was found in 42 (39\%) and in $36(17 \%)$ of the patients in the same groups, respectively. After adjusting for risk, tuberculosis survivors were 5.4 times more likely to have abnormal lung function test results than were LTBI patients ( $p>0.001 ; 95 \% \mathrm{CI}$ : 2.98 9.68). Lung damage was more common in cigarette smokers; however, after adjusting for demographic and other risk factors, that difference was not significant. The authors concluded that "microbiological cure is the beginning, not the end of their illness".

In a population-based multicenter study conducted in five Latin American cities including 5,571 subjects, a self-reported history of pulmonary tuberculosis was clearly associated with varying degrees of airflow obstruction, defined by a post-bronchodilator $\mathrm{FEV}_{1} / \mathrm{FVC}$ ratio $<0.7$. In that study, $30.7 \%$ of subjects with a history of tuberculosis presented with airflow obstruction vs. $13.6 \%$ of those without that history. The association between a self-reported history of tuberculosis and the presence of airflow obstruction remained unchanged even after adjustments for confounding variables (adjusted $\mathrm{OR}=2.33 ; 95 \% \mathrm{CI}: 1.50-3.62)$. $^{(38)}$

In Tijuana, Mexico, ${ }^{(39)} 70$ cured pulmonary tuberculosis patients were evaluated in order to determine the prevalence and the severity of COPD and its impact on QoL. Among those patients, 24 (34.3\%) had nonreversible chronic airway obstruction (mean post-bronchodilation $\mathrm{FEV}_{1}=1.3 \pm 0.6 \mathrm{~L}$ ). In addition, patients with chronic airway obstruction had a COPD assessment test score of $15.1 \pm 10.4-$ a score $\geq 10$ points indicates a significant impact on QoL. The authors concluded that functional abnormalities are frequent in tuberculosis patients, and those with chronic airway obstruction are often symptomatic and experience a significant impact on their QoL.

\section{PR INTERVENTIONS}

The mechanisms behind lung damage following tuberculosis and its treatment have been described by
Zhuk, ${ }^{(40)}$ who underlined the advantages of PR and who identified that about $50 \%$ of those patients undergo PR programs during hospital admissions in Russia.

In an experience in Japan, ${ }^{(41)}$ the effectiveness of PR was evaluated for a mean period of 3.9 weeks in 37 inpatients with pulmonary tuberculosis sequelae. The PR program included relaxation, breathing retraining, exercise training, respiratory muscle training, and educational support. Mean VC improved significantly ( $n=37$ ), from $1.48 \mathrm{~L}$ to $1.59 \mathrm{~L}$, whereas $\mathrm{FEV}_{1}$ ( $\mathrm{n}=$ 37) improved from $0.93 \mathrm{~L}$ to $1.02 \mathrm{~L}$, as well as did $\mathrm{PaO}_{2}(\mathrm{n}=35)$, from 67.1 Torr to 72.4 Torr. The gain in the 6MWD ( $n=29)$ increased from $303 \mathrm{~m}$ to $339 \mathrm{~m}$, and MIP ( $n=17$ ) increased from $38.5 \mathrm{cmH}_{2} \mathrm{O}$ to 47.5 $\mathrm{cmH}_{2} \mathrm{O}$. There were also improvements in activities of daily living, dyspnea symptoms, and QoL. The effects of PR were independent from previous thoracic surgery for tuberculosis, pattern of ventilatory impairment, findings on CXR, or degree of respiratory insufficiency. The study results suggested that PR is effective in improving pulmonary function, exercise tolerance, symptoms, and QoL in patients with pulmonary tuberculosis sequelae.

A group of authors in Colombia ${ }^{(42,43)}$ investigated the effects of PR on aerobic capacity and health-related QoL in patients with sequelae of pulmonary tuberculosis who participated in an eight-week PR program within a public hospital. The studies included a pre- and posttest design without a control group, and it involved 8 participants intentionally selected from a public program. The program included physical training (upper and lower limb strengthening and aerobic component), education on tuberculosis, and training on activities of daily living. A treadmill-based training protocol for the lower limbs was established, starting with an initial intensity load of $60 \%$, and then increasing up to a load of $85 \%$; the peak oxygen consumption $\left(\mathrm{VO}_{2 \text { peak }}\right)$ was set at $90 \%$. The training sessions were carried out three times a week for eight weeks, and each lasted one hour, which included initial examination, warm-up, exercise protocol, and stretching exercises. Outcome measures $\left(\mathrm{VO}_{2 \text { peak }}, 6 \mathrm{MWD}\right.$, and two QoL questionnaires-the Medical Outcomes Study 36-item Short-Form Health Survey [SF-36] and SGRQ)-were performed prior to the first training session and at eight weeks. Comparing baseline and final results, the $\mathrm{VO}_{2 \text { peak }}$ increased by $1.7 \mathrm{~mL} / \mathrm{kg} / \mathrm{min}(\mathrm{p}=0.039)$, and the 6MWD increased by $63.6 \mathrm{~m}(\mathrm{p}=0.014)$. The QoL questionnaire scores increased as well: SF-36 physical domain score increased by 6.98 points ( $p=0.039$ ), whereas the SGRQ score increased by 13 points ( $p=$ 0.039 ). The authors concluded that the PR program in that sample of patients with pulmonary tuberculosis sequelae resulted in significant improvements in both aerobic capacity and QoL.

A single-blinded randomized controlled study was performed at a clinic in Khayelitsha, Western Cape, South Africa, in order to assess the effects of a six-week home-based PR program in patients receiving treatment for pulmonary tuberculosis. ${ }^{(44)}$ The program included 
baseline and post-rehabilitation measurements of lung function (spirometry), of exercise tolerance (6MWT and Borg exercise exertion scale), and of health-related QoL (EuroQoL-EQ-5 D-questionnaire) in 34 patients receiving outpatient treatment for tuberculosis and in 33 controls. When compared with the controls, there were improvements in the lung function $\left(\mathrm{FEV}_{1}\right.$ and FVC), exercise tolerance, and QoL in the tuberculosis patients, although statistical significance was not reached at the end of the six-week PR program. The authors concluded that the rationale for using a PR program for patients with pulmonary tuberculosis is valid and that further evidence is needed.

In a prospective nonrandomized open trial over a nine-week period conducted in Japan, ${ }^{(45)}$ the effect of PR on patients with post-tuberculosis lung disorders was compared with that on patients with COPD. The post-tuberculosis group comprised 32 patients (25 of whom had undergone thoracoplasty; mean age $=71$ \pm 5 years; and mean $\mathrm{FEV}_{1}=0.84 \pm 0.29 \mathrm{~L}$ ) who were compared with 32 age-matched and $\mathrm{FEV}_{1}$-matched COPD patients (controls). First, the two groups were compared regarding their exercise tolerance (6MWT). Then, the patients were trained to undergo a nine-week outpatient PR program. Improvements were assessed by using clinical dyspnea ratings, a daily activity score, and the results of the 6MWT. When age and $\mathrm{FEV}_{1}$ were matched, the 6MWD did not differ between the study and control groups. After the PR program, significant improvements were observed in the two groups regarding the Medical Research Council dyspnea scale, transition dyspnea index, and daily activity scores, as well as in the 6MWD-study group $=42 \mathrm{~m}(\mathrm{p}<0.01)$ vs. control group $=47 \mathrm{~m}(p<0.01)$. The gain in the various parameters was comparable between the groups. The authors concluded that the PR program is as beneficial in post-tuberculosis patients with lung disorders as in COPD patients if the severity of the disability is similar.

\section{LTOT AND VENTILATION}

The importance of LTOT was investigated in Japan, together with the relevance of tuberculosis as a disease that demands post-treatment rehabilitation. ${ }^{(46)}$ The importance of ventilation to improve the performance of tuberculosis patients with sequelae was also studied.

In a study involving 7 patients with pulmonary tuberculosis sequelae and severe restrictive ventilatory defect, ${ }^{(47)}$ nasal intermittent positive pressure ventilation (NIPPV) was applied during exercise in order to determine whether arterial blood gas measurements, breathlessness, and exercise endurance could be improved. The authors reported that NIPPV significantly prolonged exercise endurance time and decreased breathlessness in all of the patients, as well as it significantly improved arterial blood gas measurements.

Yang et al.(48) described the positive effects of respiratory support with a poncho (wraparound) ventilator and mouthpiece intermittent positive pressure ventilation on a 44-year-old patient affected by severe restrictive lung disease secondary to right phrenic nerve crush/pneumoperitoneum and left pneumonectomy/ decortication for bilateral lower lobe tuberculosis. The patient developed dyspnea, coryza, and somnolence. With the assistance of the two respiratory devices, the patient was able to complete her education, get married, and lead a fulfilling life in the community.

\section{PHYSIOTHERAPY}

In 2004, Strelis et al. ${ }^{(49)}$ proposed a vibration massage-based method to prevent early postresection complications after surgical interventions due to tuberculosis. The method included the use of a light vibromassage apparatus that allowed systemic physiotherapy involving electric vibroacupressure of the whole circumference of the chest. In that case-control study, ${ }^{(49)}$ early postresection complications were significantly less frequently observed in the study group than in the control group ( $60 \mathrm{vs.} 50$ patients). The procedure reduced the likelihood of development of a number of pleuropulmonary events (atelectasis, nonspecific pneumonia, residual postresection pleural cavity, and bronchial fistulas) and enhanced the functional status of the patients.

\section{MDR-TB}

The majority of the studies included in the present review article reported drug-susceptible cases. Only three studies discussed PR interventions in MDR-TB patients.

In a cross-sectional cohort study in Brazil,(50) respiratory function, functional capacity, and QoL were investigated in 18 patients who had been treated for pulmonary MDR-TB for 18 months or more. The subjects underwent the following assessments: forced spirometry, CXR, 6MWT, bioelectrical impedance analysis, MIP, and MEP. They also completed a health-related QoL questionnaire. Spirometric evaluation showed that $78 \%$ of the subjects had abnormal ventilatory patterns. All of the subjects presented with significantly decreased MIP and MEP, despite the fact that their nutritional status was within the normal range. In $72 \%$ of the subjects, the 6MWD was lower than expected, and residual lesions were present in $100 \%$, whereas $78 \%$ reported a worsening in their QoL. The authors concluded that patients achieving MDR-TB cure present impaired respiratory function, as well as mildly reduced functional capacity and QoL, suggesting that a portion of these patients might require PR.

In a cross-sectional study in India, ${ }^{(51)} 130$ MDR-TB patients who had initiated treatment were evaluated between 2002 and 2006. During the study period, 24 patients died, and 63 (59\%) could be traced, of whom 51 were alive. Those patients had completed a mean post-treatment period of $24.0 \pm 14.7$ months (range, 6-63 months), 40 (78\%) had persistent respiratory symptoms, and $50(98 \%)$ had residual sequelae on CXR ( $40 \%$ of which being severe). Abnormal pulmonary 
function test results were observed in 45 (96\%) of the patients, predominantly with a mixed type ventilatory impairment in $31(66 \%)$, a pure restrictive pattern in $9(19 \%)$, and a pure obstructive pattern in 5 (11\%). The authors concluded that functional impairment and radiological lesions are common in patients after completing MDR-TB treatment.

In a case report in Colombia, ${ }^{(52)}$ a patient with MDR-TB underwent a PR program. After the completion of the program, there was improvement in the 6MWD (from $240 \mathrm{~m}$ to $350 \mathrm{~m}$ ), in the Medical Research Council dyspnea scale score (from 4 to 1 ), and in the Borg scale (from 7 to 0). Furthermore, his upper and lower limb muscle strength increased from 3 to 4 . The authors concluded that a period of PR lasting 8-10 weeks was sufficient to improve his functionality.

A cross-sectional study carried out in Brazil(53) compared functional and respiratory changes between patients with a single episode of tuberculosis and MDR-TB patients who had had multiple episodes before receiving an effective treatment. The MDR-TB group showed significantly lower values in FVC $(72.06 \% \pm$ $14.95 \%$ vs. $43.58 \% \pm 16.03 \%$ of predicted), FEV $_{1}$ $(66.13 \% \pm 19.87 \%$ vs. $33.08 \% \pm 15.64 \%$ of predicted $)$, and 6MWD (484.21 m $\pm 74.01 \mathrm{~m}$ vs. $334.75 \mathrm{~m} \pm$ $104.07 \mathrm{~m}$ ). The study ${ }^{(53)}$ demonstrated the existence of significant functional limitations in MDR-TB patients who had undergone multiple tuberculosis treatments and strengthened the importance to prevent treatment noncompliance and subsequent rescue regimens.

In a study in Limpopo Province, South Africa, ${ }^{(54)} 33$ MDR-TB patients performed spirometry: 14 (42\%) had a restrictive pattern, 4 (12\%) had obstructive disease, and 13 (39\%) showed a combined pattern, although no further studies were performed to corroborate the presence of restriction. In the linear regression analysis, $\mathrm{FEV}_{1}$ and FVC (both in \% of predicted) were negatively associated with the time between the first diagnosis of tuberculosis and the completion of treatment (mean time, 51.8 months). The authors concluded that residual lung damage in MDR-TB patients is common and that extensive efforts should be made in order to ensure rapid diagnosis and treatment. ${ }^{(54)}$

\section{FINAL CONSIDERATIONS}

The present review of the evidence available in the literature suggests that tuberculosis is definitively responsible for lung function sequelae, most of which causing an obstructive pattern, although restrictive and mixed patterns are also present.

Unfortunately, few studies are available in the literature investigating the physiopathology of obstruction, the potential need for PR, and the effects of a PR program. The majority of the studies investigated the functional status by spirometry, a few of them by plethysmography, whereas evidence based on determination of DLCO, arterial blood gas analyses, walk tests, and QoL is anecdotal.
The vast majority of the available studies included patients with drug-susceptible tuberculosis. Details on the characteristics of tuberculosis are rarely complete; in particular, information on the microbiological confirmation of the cases (culture or, at least, sputum smear microscopy) is rarely reported, since most studies tend to focus on the physiopathological aspects of the patients studied. We have found no studies in which a diagnosis of tuberculosis was based on rapid molecular assays, such as Xpert ${ }^{\text {TM }}$ MTB/RIF as of today. ${ }^{(55)}$

Very few studies reported MDR-TB cases, and we have found no studies that investigated whether there is any difference in sequelae between drug-susceptible tuberculosis and MDR-TB cases. The latter patients need a much longer period of treatment (18-24 months in comparison with the tentative 6 months for drug-susceptible cases) and have usually completed more than one previous course of treatment with first or second-line antituberculosis drugs. The impact of the shorter tuberculosis regimen (known as the Bangladesh regimen), which has a duration comparable to that for drug-susceptible tuberculosis ( 9 months), could not be evaluated since it was recommended by WHO only in May of 2016. $10,56,57)$

Interestingly, although all studies identified that tuberculosis plays a significant role in deteriorating pulmonary function, the additional role of smoking as a factor that creates additional lung function impairment needs to be studied further.

It is recommended that any future evaluation of tuberculosis and MDR-TB sequelae include complete information on

a) The characteristics of the patients (age, sex, ethnicity, etc.)

b) A complete description of the disease, including history of previous treatments, bacteriological status, pattern of drug resistance, and history of current treatment (drugs and regimen) with an emphasis on adverse events and their management

c) A complete description of the physiopathological status of the patients, including spirometry (and bronchodilator response), assessment of lung volumes (plethysmography or others), determination of DLCO, arterial blood gas analysis, 6MWT, radiological evaluation (ideally including CXR), and QoL evaluated with a general instrument and a specific respiratory instrument (SGRQ or others)

d) Rationale and consistence of the proposed PR plan, with clear pre- and post-test comparisons and evaluation of costs

e) Ideally, further studies should include the number of patients who need PR, since this will help to estimate the need for PR planning

\section{ACKNOWLEDGEMENTS}

The present review article was developed within the Asociación Latinoamericana del Tórax (ALAT)/ERS Collaborative LATSINTB project. 


\section{REFERENCES}

1. World Health Organization. Global tuberculosis report 2015. WHO/ HTM/TB/2015.22. Geneva: World Health Organization; 2015.

2. Migliori GB, Sotgiu G, Gandhi NR, Falzon D, DeRiemer K, Centis R, et al. Drug resistance beyond extensively drug-resistant tuberculosis: individual patient data meta-analysis. Eur Respir J. 2013;42(1):16979. http://dx.doi.org/10.1183/09031936.00136312

3. Sotgiu G, Mauch V, Migliori GB, Benedetti A. Evidence-based agreed-upon health priorities to remedy the tuberculosis patient's economic disaster. Eur Respir J. 2014;43(6):1563-6. http://dx.doi. org/10.1183/09031936.00064314

4. Lönnroth K, Migliori GB, Abubakar I, D’Ambrosio L, de Vries G, Diel $R$, et al. Towards tuberculosis elimination: an action framework for low-incidence countries. Eur Respir J. 2015;45(4):928-52. http:// dx.doi.org/10.1183/09031936.00214014

5. D'Ambrosio L, Dara M, Tadolini M, Centis R, Sotgiu G, van der Werf MJ, et al. Tuberculosis elimination: theory and practice in Europe. Eur Respir J. 2014;43(5):1410-20. http://dx.doi org/10.1183/09031936.00198813

6. Migliori GB, Zellweger JP, Abubakar I, Ibraim E, Caminero JA, De Vries $\mathrm{G}$, et al. European union standards for tuberculosis care. Eur Respi J. 2012;39(4):807-19. http://dx.doi.org/10.1183/09031936.00203811

7. Schito M, Migliori GB, Fletcher HA, McNerney R, Centis R, D'Ambrosio L, et al. Perspectives on Advances in Tuberculosis Diagnostics, Drugs, and Vaccines. Clin Infect Dis. 2015;61 Suppl 3:S102-18. http://dx.doi.org/10.1093/cid/civ609

8. Falzon D, Jaramillo E, Schünemann HJ, Arentz M, Bauer M, Bayona $J$, et al. WHO guidelines for the programmatic management of drugresistant tuberculosis: 2011 update. Eur Respir J. 2011;38(3):516-28. http://dx.doi.org/10.1183/09031936.00073611

9. Pontali E, Sotgiu G, D'Ambrosio L, Centis R, Migliori GB. Bedaquiline and multidrug-resistant tuberculosis: a systematic and critical analysis of the evidence. Eur Respir J. 2016;47(2):394-402. http:// dx.doi.org/10.1183/13993003.01891-2015

10. Sotgiu G, Tiberi S, D'Ambrosio L, Centis R, Zumla A, Migliori $\mathrm{GB}$. WHO recommendations on shorter treatment of multidrug resistant tuberculosis. Lancet. 2016;387(10037):2486-7 http://dx.doi. org/10.1016/S0140-6736(16)30729-2

11. DANIELS M. Tuberculosis in Europe during and after the second world war. $\mathrm{Br}$ Med J. 1949;2(4637):1135-40. http://dx.doi. org/10.1136/bmj.2.4637.1135

12. CHAPMAN CE, HOLLANDER AG. TUBERCULOSIS AND REHABILITATION: DYNAMIC PHYSICAL RESTORATION OF PATIENTS WITH ACTIVE DISEASE. Calif Med. 1964;100:88-91.

13. Mohan A, Premanand R, Reddy LN, Rao MH, Sharma SK, Kamity $\mathrm{R}$, et al. Clinical presentation and predictors of outcome in patients with severe acute exacerbation of chronic obstructive pulmonary disease requiring admission to intensive care unit. BMC Pulm Med. 2006;6:27. http://dx.doi.org/10.1186/1471-2466-6-27

14. Jordan TS, Spencer EM, Davies P. Tuberculosis, bronchiectasis and chronic airflow obstruction. Respirology. 2010;15(4):623-8. http:// dx.doi.org/10.1111/j.1440-1843.2010.01749.x

15. Hassan IS, Al-Jahdali HH. Obstructive airways disease in patients with significant post- tuberculous lung scarring. Saudi Med J. 2005;26(7):1155-7

16. Shah M, Reed C. Complications of tuberculosis. Curr Opin Infect Dis. 2014;27(5):403-10. http://dx.doi.org/10.1097/ QC0.0000000000000090

17. Bansal V, Prasad R. Pulmonary rehabilitation in chronic respiratory diseases. Indian J Chest Dis Allied Sci. 2014;56(3):147-8.

18. Spruit MA, Singh SJ, Garvey C, ZuWallack R, Nici L, Rochester C, et al. An official American Thoracic Society/European Respiratory Society statement: key concepts and advances in pulmonary rehabilitation. Am J Respir Crit Care Med. 2013;188(8):e13-64 Erratum in: Am J Respir Crit Care Med. 2014;189(12):1570. http:// dx.doi.org/10.1164/rccm.201309-1634ST

19. Abdool-Gaffar MS, Ambaram A, Ainslie GM, Bolliger CT, Feldman C, Geffen $\mathrm{L}$, et al. Guideline for the management of chronic obstructive pulmonary disease--2011 update. S Afr Med J. 2011;101(1 Pt 2):6373.

20. Subotic D, Yablonskiy P, Sulis G, Cordos I, Petrov D, Centis R, et al. Surgery and pleuro-pulmonary tuberculosis: a scientific literature review. J Thorac Dis. 2016;8(7):E474-85. http://dx.doi.org/10.21037/ jtd.2016.05.59

21. Rhee CK, Yoo KH, Lee JH, Park MJ, Kim WJ, Park YB, et al. Clinical characteristics of patients with tuberculosis-destroyed lung. Int J Tuberc Lung Dis. 2013;17(1):67-75. http://dx.doi.org/10.5588/ ijtld.12.0351

22. Lee $\mathrm{JH}$, Chang $\mathrm{JH}$. Lung function in patients with chronic airflow obstruction due to tuberculous destroyed lung. Respir Med. 2003;97(11):1237-42. http://dx.doi.org/10.1016/S0954 6111(03)00255-5

23. Báez-Saldaña $R$, López-Arteaga $Y$, Bizarrón-Muro A, FerreiraGuerrero E, Ferreyra-Reyes L, Delgado-Sánchez G, et al. A nove scoring system to measure radiographic abnormalities and related spirometric values in cured pulmonary tuberculosis. PLoS One. 2013;8(11):e78926. http://dx.doi.org/10.1371/journal.pone.0078926

24. HALLETT WY, MARTIN CJ. The diffuse obstructive pulmonary syndrome in a tuberculosis sanatorium. I. Etiologic factors. Ann Intern Med. 1961;54:1146-55. http://dx.doi.org/10.7326/0003-4819 54-6-1146

25. Willcox PA, Ferguson AD. Chronic obstructive airways disease following treated pulmonary tuberculosis. Respir Med. 1989;83(3):195-8. http://dx.doi.org/10.1016/S0954-6111(89)80031-9

26. Hnizdo $E$, Singh T, Churchyard G. Chronic pulmonary function impairment caused by initial and recurrent pulmonary tuberculosis following treatment. Thorax. 2000;55(1):32-8. http://dx.doi. org/10.1136/thorax.55.1.32

27. Amaral AF Coton S, Kato B Tan WC, Studnicka M, Janson C et al. Tuberculosis associates with both airflow obstruction and low lung function: BOLD results. Eur Respir J. 2015;46(4):1104-12. http:// dx.doi.org/10.1183/13993003.02325-2014

28. Jung JW, Choi JC, Shin JW, Kim JY, Choi BW, Park IW. Pulmonary Impairment in Tuberculosis Survivors: The Korean Nationa Health and Nutrition Examination Survey 2008-2012. PLoS One. 2015;10(10):e0141230. http://dx.doi.org/10.1371/journal. pone. 0141230

29. Sailaja K, Nagasreedhar Rao H. Study of pulmonary function impairment by spirometry in post pulmonary tuberculosis. J Evolution Med Dent Sci. 2015;4(42):7365-70. http://dx.doi.org/10.14260/ jemds/2015/1068

30. Pefura-Yone EW, Kengne AP, Tagne-Kamdem PE, Afane-Ze E. Clinical significance of low forced expiratory flow between $25 \%$ and $75 \%$ of vital capacity following treated pulmonary tuberculosis: a cross-sectional study. BMJ Open. 2014;4(7):e005361. http://dx.doi. org/10.1136/bmjopen-2014-005361

31. Ralph AP, Kenangalem E, Waramori G, Pontororing GJ, Sandjaja, Tjitra $\mathrm{E}$, et al. High morbidity during treatment and residual pulmonary disability in pulmonary tuberculosis: under-recognised phenomena. PloS One. 2013;8(11):e80302. http://dx.doi.org/10.1371/journal. pone.0080302

32. Vecino M, Pasipanodya JG, Slocum P, Bae S, Munguia G, Miller T, et al. Evidence for chronic lung impairment in patients treated for pulmonary tuberculosis. J Infect Public Health. 2011;4(5-6):244-52. http://dx.doi.org/10.1016/j.jiph.2011.08.005

33. Lee SW, Kim YS, Kim DS, Oh YM, Lee SD. The risk of obstructive lung disease by previous pulmonary tuberculosis in a country with intermediate burden of tuberculosis. J Korean Med Sci. 2011;26(2):268-73. http://dx.doi.org/10.3346/jkms.2011.26.2.268

34. Chung KP, Chen JY, Lee CH, Wu HD, Wang JY, Lee LN, et al. Trends and predictors of changes in pulmonary function after treatment for pulmonary tuberculosis. Clinics (Sao Paulo). 2011;66(4):549-56. http://dx.doi.org/10.1590/S1807-59322011000400005

35. Lam KB, Jiang CQ, Jordan RE, Miller MR, Zhang WS, Cheng KK, et al Prior TB, smoking, and airflow obstruction: a cross-sectional analysis of the Guangzhou Biobank Cohort Study. Chest. 2010;137(3):593600. http://dx.doi.org/10.1378/chest.09-1435

36. Baig IM, Saeed W, Khalil KF. Post-tuberculous chronic obstructive pulmonary disease. J Coll Physicians Surg Pak. 2010;20(8):542-4.

37. Pasipanodya JG, Miller TL, Vecino M, Munguia G, Garmon $R$ Bae $S$, et al. Pulmonary impairment after tuberculosis. Chest. 2007;131 (6):1817-24. http://dx.doi.org/10.1378/chest.06-2949

38. Menezes AM, Hallal PC, Perez-Padilla R, Jardim JR, Muiño A, Lopez $\mathrm{MV}$, et al. Tuberculosis and airflow obstruction: evidence from the PLATINO study in Latin America. Eur Respir J. 2007;30(6):1180-5. http://dx.doi.org/10.1183/09031936.00083507

39. de la Mora IL, Martínez-Oceguera D, Laniado-Laborín R. Chronic airway obstruction after successful treatment of tuberculosis and its impact on quality of life. Int J Tuberc Lung Dis. 2015;19(7):808-10. http://dx.doi.org/10.5588/ijtld.14.0983

40. Zhuk NA. Respiratory function rehabilitation: a component of 
treatment for tuberculosis [Article in Russian]. Probl Tuberk Bolezn Legk. 2007;(6):25-8.

41. Tada A, Matsumoto H, Soda R, Endo S, Kawai H, Kimura G, et al. Effects of pulmonary rehabilitation in patients with pulmonary tuberculosis sequelae [Article in Japanese]. Nihon Kokyuki Gakkai Zasshi. 2002;40(4):275-81.

42. Rivera Motta JA, Wilches EC, Mosquera RP. Pulmonary rehabilitation on aerobic capacity and health-related quality of life in patients with sequelae of pulmonary TB [abstract]. Am J Respir Crit Care Med. 2016;193:A2321.

43. Rivera JA, Wilches-Luna EC, Mosquera R, Hernandez NL, Hernandez Orobio OM. Pulmonary rehabilitation on aerobic capacity and healthrelated quality of life in patients with sequelae of pulmonary TB [abstract]. Physiotherapy. 2015;101:(Suppl 1):e1288. http://dx.doi. org/10.1016/j.physio.2015.03.1203

44. de Grass D, Manie S, Amosun SL. Effectiveness of a home-based pulmonary rehabilitation programme in pulmonary function and health related quality of life for patients with pulmonary tuberculosis: a pilot study. Afr Health Sci. 2014;14(4):866-72. http://dx.doi. org/10.4314/ahs.v14i4.14

45. Ando M, Mori A, Esaki H, Shiraki T, Uemura H, Okazawa M, et al. The effect of pulmonary rehabilitation in patients with post-tuberculosis lung disorder. Chest. 2003;123(6):1988-95. http://dx.doi.org/10.1378/ chest.123.6.1988

46. Kida K, Motegi T, Ishii T, Hattori K. Long-term oxygen therapy in Japan: history, present status, and current problems. Pneumonol Alergol Pol. 2013;81(5):468-78.

47. Tsuboi T, Ohi M, Chin K, Hirata H, Otsuka N, Kita H, et al. Ventilatory support during exercise in patients with pulmonary tuberculosis sequelae. Chest. 1997;112(4):1000-7. http://dx.doi.org/10.1378/ chest.112.4.1000

48. Yang GF, Alba A, Lee M. Respiratory rehabilitation in severe restrictive lung disease secondary to tuberculosis. Arch Phys Med Rehabil. 1984;65(9):556-8.
49. Strelis AA, Strelis AK, Roskoshnykh VK. Vibration massage in the prevention of postresection complications and in the clinical rehabilitation of patients with pulmonary tuberculosis after surgical interventions [Article in Russian]. Probl Tuberk Bolezn Legk. 2004;(11):29-34.

50. Godoy MD, Mello FC, Lopes AJ, Costa W, Guimarães FS, Pacheco $A G$, et al. The functional assessment of patients with pulmonary multidrug-resistant tuberculosis. Respir Care. 2012;57(11):1949-54. http://dx.doi.org/10.4187/respcare.01532

51. Singla N, Singla R, Fernandes S, Behera D. Post treatment sequelae of multi-drug resistant tuberculosis patients. Indian J Tuberc. 2009;56(4):206-12.

52. Wilches EC, Rivera JA, Mosquera R, Loaiza L, Obando L. Pulmonary rehabilitation in multi-drug resistant tuberculosis (TB MDR): a case report. Colomb Med. 2009;40(4):436-41.

53. Di Naso FC, Pereira JS, Schuh SJ, Unis G. Functional evaluation in patients with pulmonary tuberculosis sequelae [Article in Portuguese]. Rev Port Pneumol. 2011;17(5):216-21. http://dx.doi. org/10.1016/j.rppneu.2011.06.010

54. de Vallière S, Barker RD. Residual lung damage after completion of treatment for multidrug-resistant tuberculosis. Int J Tuberc Lung Dis. 2004;8(6):767-71.

55. Weyer K, Mirzayev F, Migliori GB, Van Gemert W, D'Ambrosio L, Zignol $M$, et al. Rapid molecular TB diagnosis: evidence, policy making and global implementation of Xpert MTB/RIF. Eur Respir $\mathrm{J}$. 2013;42(1):252-71. http://dx.doi.org/10.1183/09031936.00157212

56. World Health Organization. WHO treatment guidelines for drugresistant tuberculosis 2016 update. WHO/HTM/TB/2016.04. Geneva: World Health Organization; 2016

57. Sotgiu G, Tiberi S, D'Ambrosio L, Centis R, Alffenaar JW, Caminero $\mathrm{JA}$, et al. Faster for less: the new 'shorter' regimen for multidrugresistant tuberculosis. Eur Respir J. 2016. Epub 2016 Sep 1. pii: ERJ 01249-2016. http://dx.doi.org/ 10.1183/13993003.01249-2016 